\title{
MAPS; acute safety data of the St Jude accent - tendril IPG system during prolonged max power CMR scanning
}

\author{
Mark P Ainslie ${ }^{1,2^{*}}$, Anna Reid ${ }^{1,2}$, Christopher A Miller ${ }^{1,2}$, David Clark, Benjamin Brown¹, David Fox ${ }^{1}$, Neil Davidson', \\ Andrew Trafford ${ }^{2}$, Matthias Schmitt ${ }^{1,2}$
}

From 18th Annual SCMR Scientific Sessions

Nice, France. 4-7 February 2015

\section{Background}

Until recently, the use of MRI in patients with PPM's was prohibited. The lifetime probability of a patient with a cardiac device requiring an MRI is $50-75 \%$. Serious adverse events occurring during MRI of patients with cardiac devices are rare, but include asystole, VF and death. There is a clinical need to develop knowledge of MR safe devices and safe scanning protocols.

This study specifically address these issues in the SJM Accent MR PPM System, undergoing a dedicated CMR scan at $1.5 \mathrm{~T}$, with a long scan duration at max power.

\section{Methods}

Patients were recruited into the MAPS trial and implanted with a SJM Accent ppm and 2 tendril MR leads. All patients were PPM dependent. CMR was performed more than 6 weeks following implant. Pacing capture thresholds, impedances and battery voltages were assessed prior to, between and immediately following the CMR scan. The scans were performed on a Siemens Avanto 1.5T scanner. All patients were placed in an MR pacing mode. Each scan duration was over 90 mins.

\section{Results}

Between February 2012 and February 2014, 50 patients were implanted with the SJM MR ppm. The mean age of the patients was $67.3 \pm 8.1$ years, 30 male. All 50 patients had at least $1 \mathrm{CMR}$.

There were no significant adverse events reported during any of the scans and no loss of capture was seen in any scan.

${ }^{1}$ Cardiology, UHSM, Manchester, UK

Full list of author information is available at the end of the article

\section{Pacing thresholds}

The mean pacing threshold for RVOT lead at implant was $0.67 \pm 0.22 \mathrm{~V}$ and at 2 week check was $0.73 \pm 0.21 \mathrm{~V}$. Pacing thresholds prior to the $1^{\text {st }}$ CMR scan, between the lead switch over and following the scan were 0.66 $\pm 0.16 \mathrm{~V}, 0.66 \pm 0.16 \mathrm{~V}$ and $0.69 \pm 0.27 \mathrm{~V}$ respectively, $\mathrm{p}=0.34$.

The mean pacing threshold for the apical lead at implant was $0.71 \pm 0.29 \mathrm{~V}$ and at 2 week check was $0.74 \pm 0.26 \mathrm{~V}$. Pacing thresholds prior to the $1^{\text {st }}$ CMR scan, between the lead switch over and following the scan were $0.69 \pm 0.17 \mathrm{~V}$, $0.69 \pm 0.16 \mathrm{~V}$ and $0.69 \pm 0.16 \mathrm{~V}$ respectively, $\mathrm{p}=1$.

\section{Impedance}

The mean pacing impedance for the RVOT lead at implant was $739 \pm 168 \Omega$ and at 2 week check was $655 \pm 251 \Omega$. Pacing impedances prior to the CMR scan, between the lead switch over and following the scan were $601 \pm 123 \Omega$, $595 \pm 114 \Omega$ and $579 \pm 141 \Omega$ respectively, $\mathrm{p}=0.008$.

The mean pacing impedance for Apical lead at implant was $631 \pm 130 \Omega$ and at 2 week check was $616 \pm 81 \Omega$. Pacing impedances prior to the CMR scan, between the lead switch over and following the scan were $612 \pm 81 \Omega$, $611 \pm 80 \Omega$ and $574 \pm 69 \Omega$ respectively, $\mathrm{p}=0.004$.

\section{Battery}

The mean battery voltage prior to, between and following every CMR scan did not alter acutely. CMR scan 1 was at $2.99 \pm 0.03 \mathrm{~V}$.

Specific absorption rate

The max SAR of $4 \mathrm{w} / \mathrm{kg}$ was never exceeded. See Fig 1.

Tendril leads 5 control patients had the MR system but no CMR scans. Table 1 compares the parameters between cohorts over 12 months. A similar trend in 


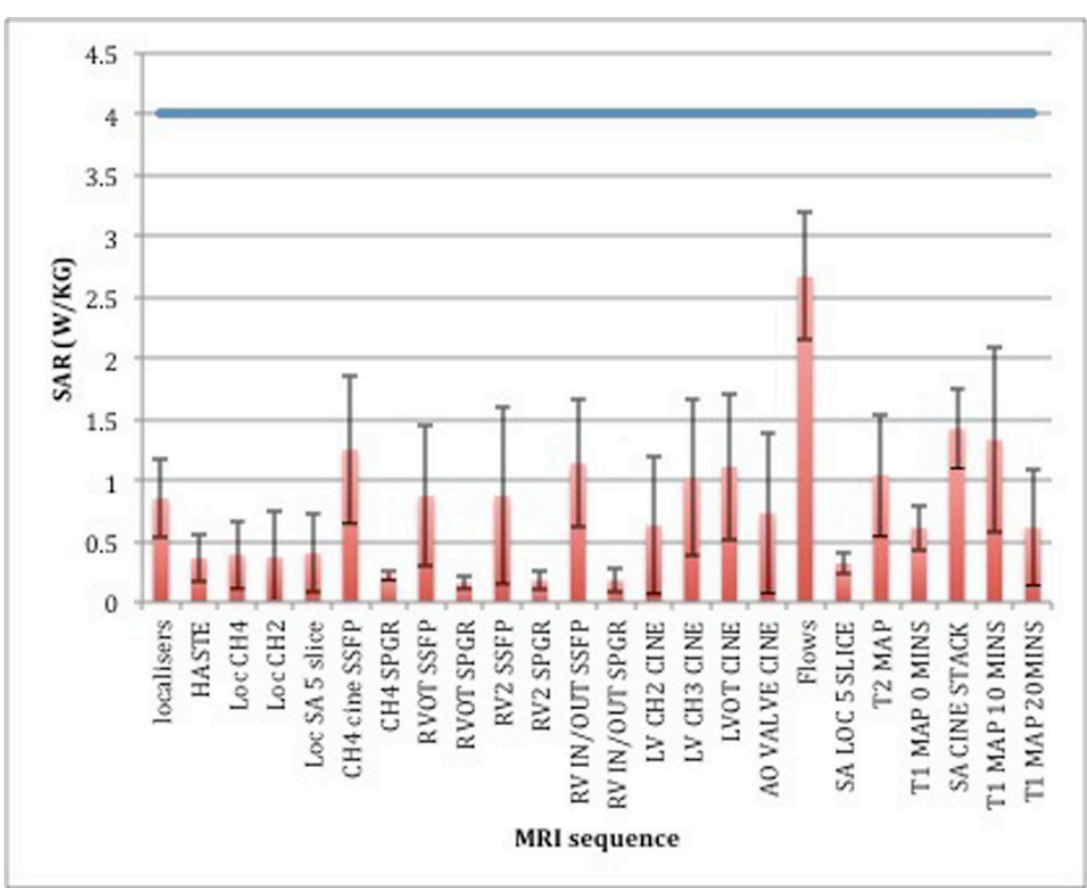

Figure 1 illustrates the Mean SAR of the different MR sequences for 10 scans.

Table 1 Control group of 5 patients with MR system but no CMR scans compared to study group.

\begin{tabular}{lcccc}
\hline & & 0 months & 2 months & 12 months \\
\hline Threshold $(V)$ & Control & $0.625+/-0.14$ & $0.6 \pm 04$ & $0.65 \pm 0.3$ \\
\hline & CMR group & $0.67 \pm 0.16$ & $0.67 \pm 0.2$ & $0.7 \pm 0.48$ \\
\hline Impedance $\Omega$ & Control & $698 \pm 135$ & $568 \pm 85$ & $537 \pm 92$ \\
\hline & CMR group & $739 \pm 167$ & $585 \pm 108$ & $558 \pm 154$ \\
\hline Battery $(V)$ & Control & 2.99 & 2.99 & 2.96 \\
\hline & CMR group & 3 & 3 & 2.96 \\
\hline
\end{tabular}

parameter changes was observed between the CMR and non-CMR pacing cohort.

\section{Conclusions}

Prolonged max power CMR scanning of the St Jude Accent - Tendril IPG system at $1.5 \mathrm{~T}$ is safe and has no clinically relevant effects on PCT, voltage and Battery power.

\section{Funding}

British Heart Foundation St Jude Fellowship Grant.

\section{Authors' details}

${ }^{1}$ Cardiology, UHSM, Manchester, UK. University of Manchester, Manchester, UK.

Published: 3 February 2015
doi:10.1186/1532-429X-17-S1-M6

Cite this article as: Ainslie et al:: MAPS; acute safety data of the St Jude accent - tendril IPG system during prolonged max power CMR scanning. Journal of Cardiovascular Magnetic Resonance 2015 17(Suppl 1): M6.
Submit your next manuscript to BioMed Central and take full advantage of:

- Convenient online submission

- Thorough peer review

- No space constraints or color figure charges

- Immediate publication on acceptance

- Inclusion in PubMed, CAS, Scopus and Google Scholar

- Research which is freely available for redistribution 